\title{
Novel Cystatin B Mutation and Diagnostic PCR Assay in an Unverricht-Lundborg Progressive Myoclonus E pilepsy Patient
}

Irina N. Bespalova, ${ }^{1}$ Steve Adkins, ${ }^{1}$ Michael Pranzatelli, ${ }^{2}$ and Margit Burmeister ${ }^{1,3 *}$

${ }^{1}$ Mental Health Research Institute, Department of Human Genetics, University of Michigan, Ann Arbor, Michigan ${ }^{2}$ National Pediatric Myoclonus Center, Washington, D.C.

${ }^{3}$ Department of Psychiatry, University of Michigan, Ann Arbor, Michigan

Two mutations in the cystatin B gene, a $\mathbf{3}^{\prime}$ splice mutation and a stop codon mutation, were previously found in patients with progressive myoclonus epilepsy of UnverrichtLundborg type [Pennacchio et al . (1996): Science 271:1731-1734]. We present here a new

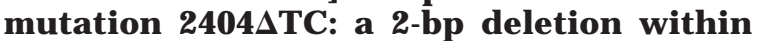
the third exon of the cystatin B gene in an Unverricht-Lundborg patient. This mutation results in a frameshift and consequently premature termination of protein synthesis. Complete sequencing of the coding region and splice junctions of the cystatin B gene showed that neither of the two previously known mutations was present in this patient. The level of cystatin B mRNA in an immortalized cell line was found to be decreased, as had been reported for other Unverricht-Lundborg patients. The new mutation further supports the argument that defects in the cystatin B gene cause the Unverricht-Lundborg form of progressive myoclonus epilepsy. We describe a simple PCR method which can detect the 2404 1 TC deletion. This assay, together with previously described PCR assays for the other two known mutations, should prove useful in confirming clinically difficult diagnoses of Unverricht-Lundborg disease. Am. J . Med. Genet. 74:467-471, 1997.

(c) 1997 Wiley-Liss, Inc.

KEY WORDS: EPM1; myoclonus epilepsy; cystatin B; deletion; mutation

Contract grant sponsor: Epilepsy Foundation of America; Contract grant sponsor: Klingenstein Foundation; Contract grant sponsor: NIH; Contract grant numbers: NS32130, TG-MH 15794.

*Correspondence to: Margit Burmeister, Mental Health Research Institute, University of Michigan, 205 Zina Pitcher Place, Ann Arbor, MI 48109-0720. E-mail: Margit@umich.edu

Received 6 J anuary 1997; Revised 25 March 1997

\section{INTRODUCTION}

Progressive myoclonus epilepsy (PME) of the Unverricht-Lundborg type $(U-L)$ is an inherited autosomal recessive disorder (gene locus EPM 1) characterized by stimulus-sensitive myoclonus, tonic-clonic seizures, and a progressive course beginning about age 6-15 years [Koskiniemi, 1974; N orio and Koskiniemi, 1979]. The disease is rare worldwide but more common in Baltic countries and Finland [Eldridge et al., 1983], affecting approximately 1 in 20,000 individuals in Finland. In the Mediterranean it is known as Mediterranean myoclonus (previously reported as a subgroup of Ramsay Hunt syndrome [Roger et al., 1968; Malafosse et al., 1992]). By genetic linkage analysis the putative EPM 1 gene was mapped to a 0.3-cM region on human chromosome 21 [Lehesjoki et al., 1993]. Applying linkage disequilibrium and hapl otype analysis to the Finnish population and searching for highly polymorphic markers using a contiguous array of cosmid, BAC, and P1 clones [Stone et al., 1996] narrowed the EPM 1 locus to a 175-kb segment [Virtaneva et al., 1996]. Recently, the gene encoding cystatin B, a 98-amino acid cysteine protease inhibitor, was localized to this region, and two cystatin B point mutations in U-L patients were identified: a splice site mutation and a stop codon mutation [Pennacchio et al., 1996]. These nucleotide substitutions, 1925G $\rightarrow \mathrm{C}$ and 2388C $\rightarrow \mathrm{T}$ (GenBank accession no. U 46692), are presumed to be responsible for decreased levels of cystatin B messenger RNA in affected individuals.

We describe here the complete sequencing of the cystatin $B$ coding region and splice junctions of an $U-L$ patient who has decreased cystatin B mRNA level but lacks the previously characterized mutations. This patient was found to be heterozygous for a new mutation $2404 \Delta \mathrm{TC}$, a two-base pair (bp) deletion in the third exon of the cystatin $\mathrm{B}$ gene. The mutation causes a translational frameshift and subsequent protein truncation after 74 amino acids.

We have devel oped a simple method for detecting the new 2404 $\Delta$ TC deletion. Enzymatic amplification of genomic DNA with a PCR primer having two mismatched nucleotides and a nonmismatched primer yiel ds a 204- 
TABLE I. Primers for PCR and Sequencing of Cystatin B Gene

\begin{tabular}{lllc}
\hline Primer & Orientation & \multicolumn{1}{c}{ Sequence $\left(5^{\prime} \rightarrow 3^{\prime}\right)$} & Position $^{\text {a }}$ \\
\hline pF2 & Forward & CTCCGACTGCCCCTTCCCTATC & $18-39$ \\
$51814 R 1$ & Reverse & GAGACACAGGGAAAGTTGCCATCT & $1250-1227$ \\
F11 & Forward & CCACCGTACCCAGCTGGAACTGT & $1729-1751$ \\
R1 & Reverse & CGGAGGATGACTTTGTCAGTCTTC & $2536-2513$ \\
pr194 & Forward & GTCCCTTCTTGCGGGGCCACC & $244-264$ \\
Pr585 & Reverse & CCCGAGCGGAGGGAGGCCTCT & $635-615$ \\
pr38 & Forward & GAAGTTCCCTGTGTTAAGGCCGTG & $1958-1982$ \\
pr231 & Forward & TGTGAGGCATCCCCTGCACATG & $2231-2252$ \\
pr44 & Forward & GCAGCAAGGTGACTTGGGATCAGAGG & $2303-2328$ \\
pr133 & Reverse & GATAAGGTCAAGGGCTTGTTTTCCAGAGGG & $2434-2405$ \\
\hline
\end{tabular}

aNumbering according to GenEMBL accession number U 46692.

bp product. The mismatched primer generates an $\mathrm{Xcml}$ endonuclease site only when the $2404 \Delta$ TC mutation is present, which can be detected by agarose gel electrophoresis and will be helpful for the development of a molecular diagnostic assay for progressive myoclonus epilepsy of Unverricht-Lundborg type.

\section{MATERIALS AND METHODS Subject}

The patient studied here (EP6) is described in detail as $U$-L patient 3 in a 5-hydroxy-L-tryptophan treatment trial [Pranzatelli et al., 1995]. Clinical symptomatology and exclusion of other disorders are provided there. After obtaining consent from the patient, genomic DNA was isolated from peripheral blood using standard techniques [Baas et al., 1984]. The research reported here was approved by the University of Michigan Institutional Review Board.

\section{Northern Blot Analysis}

Total RNA was isolated from lymphoblastoid cell lines using TRIzol reagent (Gibco BRL, Grand Island, NY) based on the method of Chomcynski and Sacchi [1987]. Total RNA (34 $\mu \mathrm{g})$ was denatured at $65^{\circ} \mathrm{C}$ for 10 min in 3-[N-morpholino]propanesulfonic acid (MOPS)/formamide/formaldehyde buffer and loaded on a $2 \%$ agarose $17.8 \%$ formaldehyde gel. After $15 \mathrm{hr}$ of electrophoresis, RNA was transferred to a Hybond-N nylon membrane (Amersham, Arlington Heights, IL) and fixed by baking for $2 \mathrm{hr}$ at $80^{\circ} \mathrm{C}$. The blot was hybridized to a 0.8-kb ${ }^{32} \mathrm{P}$-labeled cystatin B PCR fragment (primers F11 and R1; Table I) in ExpressHyb hybridization solution (Clontech, Palo Alto, CA), washed with $2 \times \mathrm{SSC}$ at room temperature for $40 \mathrm{~min}$, then with $0.1 \times \mathrm{SSC}$ at $50^{\circ} \mathrm{C}$ twice for $20 \mathrm{~min}$, and subjected to autoradiography. The membrane was stripped by incubation in sterile $\mathrm{H}_{2} \mathrm{O}$ containing $0.5 \%$ SDS during $10 \mathrm{~min}$ at $90-100^{\circ} \mathrm{C}$ and rehybridized to a $\beta$-actin probe (Clontech, Palo Alto, CA) under similar conditions.

\section{DNA Sequencing of PCR Products}

The coding region and intron-exon junctions of cystatin B were PCR-amplified from genomic DNA with the primers pF2, 51814R1, F11, and R1 [Pennacchio et al., 1996] (Table I).

Amplification of the $5^{\prime}$ part of the gene (primers pF 2 and $51814 \mathrm{R} 1$ ) was carried out in $50 \mu$ l with $1 \times \mathrm{PC2}$ buffer (Ab Peptides, Saint Louis, MO), $250 \mu \mathrm{M}$ dNTPs, $0.2 \mu \mathrm{M}$ primers, 5\% DMSO, 10 units KlenTaq1 ( $\mathrm{Ab}$ Peptides), and 0.2 unit Pfu polymerase (Stratagene, La J olla, CA) at $94^{\circ} \mathrm{C}$ for $3 \mathrm{~min}$ followed by 30 cycles of $94^{\circ} \mathrm{C}$ for $1 \mathrm{~min}, 67^{\circ} \mathrm{C}$ for $1 \mathrm{~min}$, and $4 \mathrm{~min}$ at $72^{\circ} \mathrm{C}$, with a final incubation for $10 \mathrm{~min}$ at $72^{\circ} \mathrm{C}$.

Amplification of the $3^{\prime}$ part of the gene (primers F 11 and R1) was carried out using the same conditions, except that $1 \times$ PC2 was replaced by $1 \times$ PEK buffer [Ponce and Micol, 1992].

PCR products were subjected to automated sequencing in both directions with PCR primers and the internal primers pr194, pr585, pr38, and pr231 (Table I).

\section{Diagnostic PCR Assay}

A 204-bp DNA fragment containing the $2404 \Delta T C$ deletion was PCR-amplified from genomic DNA using primers pr231 and pr133 (Table I). Reaction volume was $25 \mu$ l with $1 \times$ PEK buffer, $250 \mu \mathrm{M}$ dNTPs, $0.2 \mu \mathrm{M}$ primers, 5 units KlenTaq1, and 0.1 unit Pfu polymerase for 30 cycles of $94^{\circ} \mathrm{C}$ for $1 \mathrm{~min}, 67^{\circ} \mathrm{C}$ for $1 \mathrm{~min}$, and $72^{\circ} \mathrm{C}$ for $2 \mathrm{~min}$. PCR product $(2.5 \mu \mathrm{l})$ was digested in a volume of $15 \mu \mathrm{l}$ with $\mathrm{Xcml}$ using the vendor's condi-

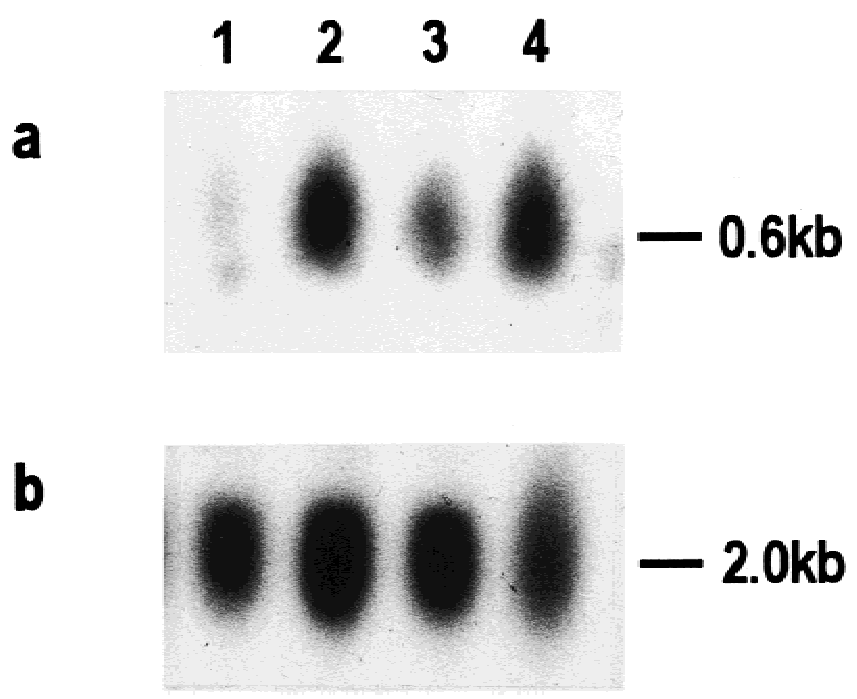

Fig. 1. Northern blot analysis of cystatin B total RNA in cell lines of one U-L affected (lane 1) and three U-L unaffected (Ianes 2-4) individuals. a: Hybridization with $3^{\prime}$ end of cystatin B gene. U-L patient shows lower level of cystatin B expression than controls. b: Hybridization of the same blot with human $\beta$-actin probe. Size of the RNA transcripts is indicated. 
tions (NEB, Beverly, MA). Digests were subjected to gel el ectrophoresis in $2.5 \%$ agarose and photographed.

\section{RESULTS AND DISCUSSION}

We examined the level of cystatin B in the immortalized Iymphoblastoid cells derived from U-L patient EP6 and from 3 unaffected individuals. The $3^{\prime}$ end of the cystatin B gene and the $\beta$-actin control probe were used to probe total RNA on a Northern blot (Fig. 1). Hybridization with cystatin B revealed a 0.6-kb transcript corresponding to the fully processed transcript of cystatin B [Ritonja et al., 1985]. The cystatin B mRNA level of patient EP6 was markedly reduced compared to the control samples (Fig. 1a), consistent with previous observations that $U-L$ patients have decreased cystatin B mRNA levels [Pennacchio et al., 1996]. Probing for $\beta$-actin confirmed that similar amounts of RNA were present in all lanes (Fig. 1b). Reduced mRNA level for cystatin B can have three causes: a defect in the promoter region for the cystatin $B$ gene, a mutation causing coding or splicing abnormalities which reduce the amount or stability of mRNA, or a large deletion or insertion, which is unlikely to be present in the region of the cystatin B gene between nucleotides 1651-2822, since no alterations were detected by Southern blot analysis of Bfal genomic DNA digests hybridized to a PCR fragment amplified with primers F 11 and R1 (data not shown). The former two cases have been observed: the stop and splice mutations were shown to reduce the mRNA amount, but patients of Finnish origin and haplotype, in which no coding or splice mutations were found, al so showed reduced mRNA amounts [Pennacchio et al., 1996] presumed to have regulatory mutations, for instance in the promoter.

For cystatin B mutation analysis of patient EP6 we screened the coding sequence of the gene and intronexon splice junctions using PCR combined with automated sequencing. For sequencing of PCR products, previously published and newly synthesized internal oligonucleotide primers were used (Table I). Sequence comparison did not reveal any of the previously described mutations in this patient: G-to-C transversion at the last nucleotide of intron 1 and change CGA to TGA, generating a translation stop codon at amino acid position 68 [Pennacchio et al., 1996]. Sequence comparison did, however, identify a new mutation, $2404 \Delta T C$, in the cystatin B gene of patient EP6: a deletion of two nucleotides in exon 3 (Fig. 2A). This mu-

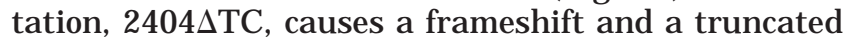

\section{(A)}

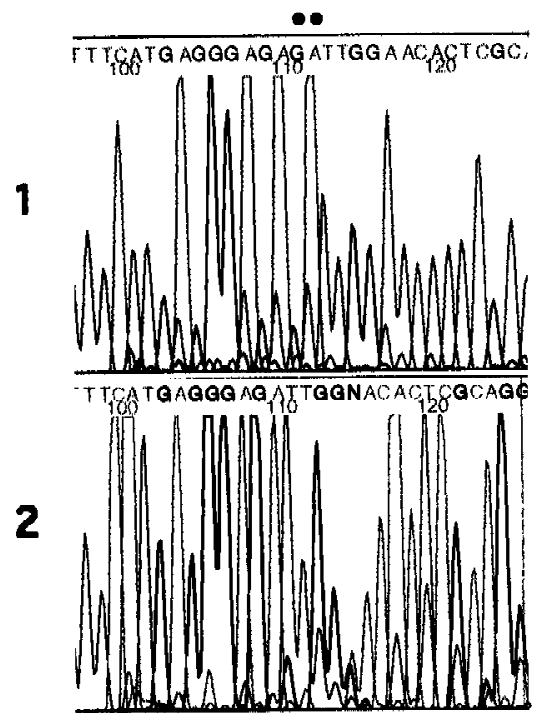

(B)

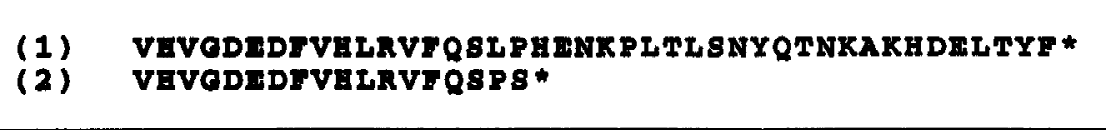

Fig. 2. A: Detection of a two-base pair (bp) deletion $2404 \Delta \mathrm{TC}$ in the coding region of the cystatin B gene. Sections of chromatograms show the nucleotide sequences of cystatin B (position 2414-2385, reverse) of a control (1) and of patient EP6 (2). Nucleotides designated by points in the sequence of the unaffected person are deleted in E p6. The heterozygous deletion causes the sequences of the two alleles to be staggered by 2 bp in the chromatogram. B: Comparison of the predicted protein sequences of exon 3 in control (1) and mutant (2) alleles. Asterisks show positions of stop codons. 
74-amino acid protein by subsequent termination of protein synthesis at the new codon TGA, 24 amino acids before the normal stop codon (Fig. 2B). No other alterations were detected in the coding region and splice junctions in the patient cystatin $B$ gene of patient EP6.

Patient EP6 was found to be heterozygous for the

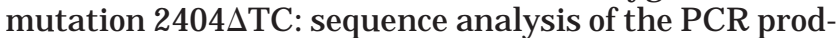
ucts demonstrated a normal sequence in addition to a 2-bp-shorter product (Fig. 2A). The other allele had no mutation in the gene regions analyzed, and thus may represent a mutation in parts of the promoter that have not yet been cloned.

Since Unverricht-Lundborg disease is usually diagnosed by clinical criteria in conjunction with exclusion of similar disorders [Pranzatelli et al., 1995], molecular diagnosis might be useful in the future. The earlierdescribed 3' splice site mutation destroys the recognition site for the restriction enzyme Bfal and the stop codon mutation creates a recognition site for BsaAI, providing a simple test for screening affected individuals [Pennacchio et al., 1996]. To establish a simple method for detecting the mutation $2404 \Delta \mathrm{TC}$ in the coding region of suspected EPM1 patients, a PCR assay was developed using primers surrounding the region of deletion (primers 231 and 133, Table I). Since a com- mercial enzyme for direct detection of the $2404 \Delta \mathrm{TC}$ mutation was not found, primers were designed in such a way that a restriction site is created in PCR fragments of affected individuals. Primer 133 contains two internal mismatches: substitution of two nucleotides on positions 2410A $\rightarrow \mathrm{T}$ and $2411 \mathrm{~T} \rightarrow \mathrm{G}$ for generation of a restriction site for the endonudease $\mathrm{Xcml}$ only in mutant alleles (Fig. 3A). When an allele with the $2404 \Delta$ TC mutation is amplified, the product is cleavable with $\mathrm{Xcml}$, in contrast to normal alleles. DNAs from patient EP6 and 3 unaffected individuals were assayed. All PCRs resulted in the expected 204-bp fragment (data not shown). After digestion with $\mathrm{Xcml}$, only patient EP6 showed an additional band of 175 bp, indicating heterozygosity for the $2404 \Delta$ TC mutation (Fig. 3B).

$2404 \Delta$ TC is the third mutation in the cystatin B gene identified to date. Haplotype analysis of specific populations [Lehesjoki et al., 1992; Malafosse et al., 1992; Pennacchio et al., 1996] suggests that there will be only a limited number of deleterious mutations in the majority of U-L patients. Therefore, it may be hoped that molecular diagnosis by simple PCR may be possible in the future.

Since submission of this paper, the mutation described here has also been found by Lalioti et al. [1997]
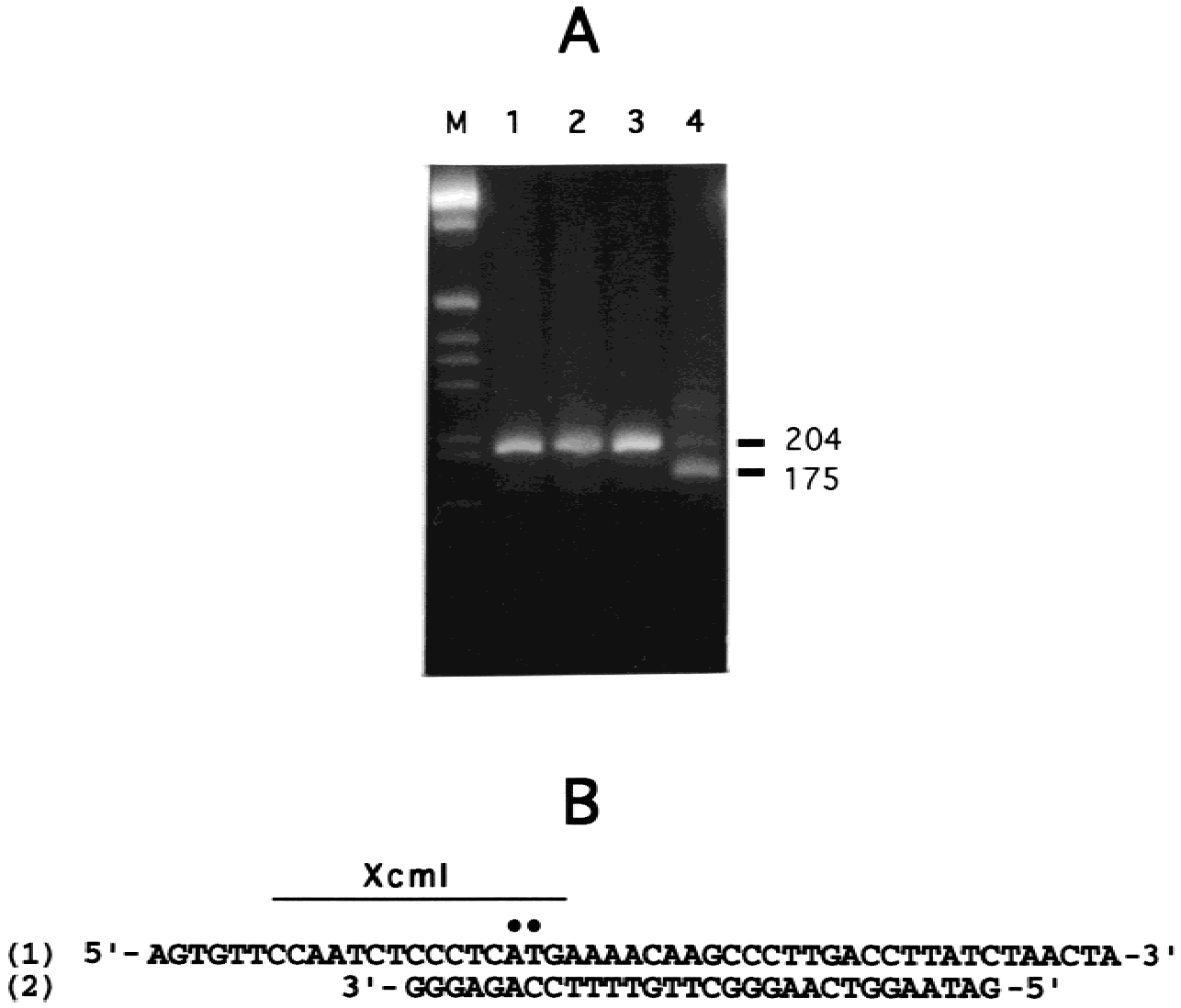

Fig. 3. Screening assay for the 2404ATC mutation by PCR followed by restriction digest. A: Genomic DNA from unaffected (lanes 1-3) and affected (lane 4) individuals was used for PCR amplification with primers 231 and 133, followed by restriction digest with Xcml. The PCR product of EP6 (lane 4) could be digested partially with Xcml (175-bp product) in contrast to control samples (lanes 1-3) in which the 204-bp product remained undigested. The additional bands of apparent higher molecular weight in lane 4 are likely the result of heteroduplex formation between the two alleles. Size marker (lane M): 1-kb DNA ladder. B: Creation of the Xcml restriction site with mismatched primer: (1) genomic sequence, (2) primer 133 sequence. Asterisks show mismatched nucleotides in the template. 
and Lafreniere et al. [1997]. Neither study describes a convenient PCR assay for this mutation. Lafreniere et al. [1997] have shown an increased expansion in the 5' end of the gene detectable by Southern blot analysis in the majority of patients, and we could now show that the second mutation in this patient also has this expansion.

\section{ACKNOWLEDGMENTS}

We thank the U-L patients and their families for their participation in these studies, the General Clinical Research Center of the University of Michigan (funded by NIH grant M01-RR00042) for Epstein-Barr virus (EBV) transformation of blood, the Family Studies Core of the University of Michigan Human Genome Center (funded by NIH grant HG00209) for facilitating patient recruitment, and Linda Harper for growing and maintaining cell lines. This work was supported by grants to M.B. from the Epilepsy Foundation of America and the NIH (NS32130), and by a Klingenstein Foundation Fellowship, and by an NIH training grant to S.A. (TG-MH15794).

\section{REFERENCES}

Baas F, Bikker H, van Ommen GJ, de Vijlder J (1984): Unusual scarcity of restriction site polymorphism in the human thyroglobulin gene. A linkage study suggesting autosomal dominance of a defective thyroglobulin allele. Hum Genet 67:301-305.

Chomczynski P, Sacchi N (1987): Single-step method of RNA isolation by acid guanidinium thiocyanate-phenol-chloroform extraction. Anal Biochem 162:156-159.

Eldridge R, Iivanainen M, Stern R, Koerber T, Wilder BJ (1983): "Baltic" myoclonus epilepsy: Hereditary disorder of childhood made worse by phenytoin. Lancet 2:838-842.

Koskiniemi M (1974): Psychological findings in progressive myoclonus epilepsy without Lafora bodies. Epilepsia 15:537-545.

Lafreniere RG, Rochefort DL, Chretien N, Rommens J M, Cochius J I, Kalviainen R, Nousiainen U, Patry G, Farrell K, Soderfeldt B, Federico A Hale BR, Cossio OH, Sorensen T, Pouliot MA, Kmiec T, Uldall P, J an szky J, Pranzatelli MR, Andermann F, Andermann E, Rouleau GA
(1997): Unstable insertion in the $5^{\prime}$ flanking region of the cystatin B gene in the most common mutation in progressive myoclonus epilepsy type 1, EPM1. Nat Genet 15:298-302.

Lalioti MD, Mirotsou M, Buresi C, Peitsch MC, Rossier C, Ouazzani R, Baldy-Moulinier M, Bottani A, Malafosse A, Antonarakis SE (1997): Identification of mutations in cystatin $B$, the gene responsible for the Unverricht-Lundborg type of progressive myoclonus epilepsy (EPM1). Am J Hum Genet 60:342-351.

Lehesjoki A-E, Koskiniemi $M$, Pandolfo $M$, Antonelli A, Kyllerman $M$, Wahlstrom J Nergardt A, Burmeister M, Sistonen P, Norio R, de la Chapelle A (1992): Linkage studies in progressive myoclonus epilepsy: Unverricht-Lundborg and Lafora's diseases. Neurology 42:1545-1550.

Lehesjoki A-E, Koskiniemi M, Norio R, Tirrito S, Sistonen P, Lander E, de la Chapelle A (1993): Localization of the EPM 1 gene for progressive myoclonus epilepsy on chromosome 21: Linkage disequilibrium allows high-resolution mapping. Hum Mol Genet 2:1229-1234.

Malafosse A, Lehesjoki A-E, Genton P, Labauge P, Durand G, Tassinari CA, Dravet CH, Michelucci R, de la Chapelle A (1992): I dentical genetic locus for Baltic and Mediterranean myoclonus. Lancet 339:1080-1081.

Norio R, Koskiniemi M (1979): Progressive myoclonus epilepsy: Genetic and nosological aspects with special reference to 107 Finnish patients. Clin Genet 15:382-398.

Pennacchio LA, Lehesjoki A-E, Stone NE, Willour VL, Virtaneva K, Miao J , D'Amato E, Ramirez L, Faham M, Koskiniemi M, Warrington J , Norio R, de la Chapelle A, Cox DR, Myers RM (1996): Mutations in the gene encoding cystatin B in progressive myoclonus epilepsy (EPM1). Science 271:1731-1734.

Ponce MR, Micol J L (1992): PCR amplification of long DNA fragments. Nucleic Acids Res 20:623.

Pranzatelli MR, Tate E, Huang Y, Haas RH, Bodensteiner J, Ashwal S, Franz D (1995): Neuropharmacology of progressive myoclonus epilepsy: Response to 5-hydroxy-I-tryptophan. E pilepsia 36:783-791.

Ritonja A, Machleidt W, Barrett AJ (1985): Amino acid sequence of the intracellular cysteine proteinase inhibitor cystatin B from human liver. Biochem Biophys Res Commun 131:1187-1192.

Roger J , Soulayrol R, Hassoun J (1968): La dyssynergie cerebelleuse myoclonique (syndrome de Ramsay Hunt). Rev Neurol (Paris) 119:85-106.

Stone NE, Fang J -B, Willour V, Pennacchio L, Warrington J, Hu A, de la Chapelle A, Lehesjoki AE, Cox DR, Myers RM (1996): Construction of a $750 \mathrm{~kb}$ bacterial clone contig and restriction map in the region of human chromosome 21 containing the progressive myoclonus epilepsy (EPM1) gene. Genome Res 6:218-225.

Virtaneva K, Miao J , Traskelin A-L, Stone N, Warrington J A, Weissenbach J, Myers RM, Cox DR, Sistonen P, de la Chapelle A, Lehesjoki A-E (1996): Progressive myoclonus epilepsy EPM 1 locus maps to a 175-kb interval in distal 21q. Am J Hum Genet 58:1247-1253. 